\title{
CIENCIAS DE LA SALUD
}

\section{Efectividad de la Hexoprenalina vs Atosiban en gestantes con amenaza de parto prematuro}

\author{
Hugo González
}

\begin{abstract}
Resumen
Introducción: El parto pretérmino es un problema de salud pública debido a las repercusiones sobre la vida del niño por causar el $75 \%$ de la morbilidad y mortalidad neonatal. Los tratamientos empleados para la amenaza de parto prematuro en el Hospital General de Luque fueron el fármaco atosiban y el fármaco hexoprenalina, no siempre existe la disponibilidad de algunos de estos fármacos de manera gratuita al alcance de las gestantes que lo requieran con el fin de evitar llegar a un parto pretérmino, medir la efectividad de los medicamentos mencionados por medio de una revisión y análisis de datos será de suma importancia para el conocimiento y la correcta elección de uno u otro fármaco para el tratamiento eficaz de parte de los profesionales de la salud en beneficio de las gestantes y del neonato.
\end{abstract}

Objetivo: Determinar la efectividad de atosiban vs hexoprenalina en el tratamiento a gestantes con amenaza de parto prematuro.

Metodología: El estudio se realizó con un enfoque cuantitativo de tipo observacional de corte transversal, retrospectivo, no se planteó hipótesis alguna en esta investigación, la muestra correspondió a la revisión de 143 fichas clínicas con diagnóstico de amenaza de parto prematuro de usuarias que han sido internadas en el Hospital de General de Luque desde el primer semestre año 2017 al primer semestre del 2019, el muestreo fue no probabilístico por conveniencia del investigador, entre las variables de estudio se puede mencionar la edad de la gestante, edad gestacional al ingreso, paridad de la gestante, procedencia, factores de riesgo como infecciones, patologías, se procedió a un plan de tabulación utilizando una planilla Excel y gestores informáticos de análisis de datos, representación gráfica por medio de tablas, posterior interpretación y discusión de datos finalizando en la conclusión y recomendación.

Resultados: 72 usuarias tratadas con atosiban no llegaron a un parto prematuro representando un 50\% mientras que 16 usuarias tratadas con este medicamento equivalente al $11 \%$ si han llegado a un parto prematuro, por otra parte 39

1. Universidad del Norte, Paraguay.

E-mail: hugonza59@gmail.com

DOI: $10.26885 /$ rcei.foro.2020.149

Trabajo publicado en acceso abierto bajo Licencia Creative Commons. 
usuarias que fueron tratadas con hexoprenalina no llegaron a un parto prematuro representando este dato al $27 \%$ y 16 de ellas que equivalen al $11 \%$ si llegaron a un parto pretérmino, con un valor $\mathrm{P}$ de 0.18 demostrando de esta manera que no hay significancia estadística en los resultados expuestos en el parto prematuro vs tratamiento. La edad gestacional donde hubieron mayores casos de amenaza de parto prematuro fueron en las 33 semanas con un $75 \%$, predominando en las usuarias de 30 años de edad con un $75 \%$, en cuanto al parto prematuro vs paridad se demostró una significancia estadística donde los casos de partos prematuros que más se presentaron fueron en las primíparas con el 8\%, en las nulíparas con el $32 \%$ que lograron superar el diagnóstico mencionado, hipertensión inducida por el embarazo con un $12 \%$ guardo relación significativa.

Conclusión: Ambos fármacos fueron efectivas para la uteroinhibición, no se puede concluir estadísticamente con este trabajo cuál de las drogas tuvo mejor efectividad ya que no se demostró una significancia estadística en los resultados analizados, un número muy importante del total de la muestra llego a un parto de termino lo que significa que hubo tiempo para llegar al objetivo más importante de un tratamiento de uteroinhibicion como lo es la maduración pulmonar del feto o su eventual traslado a un centro de atención de mayor complejidad.

Palabras clave: parto prematuro, atosiban, hexoprenalina.

\section{Referencias}

Ibarra, H., Aparicio, C., Acosta, M. (2009). Perinatal Outcome in Preterm Labor. Experience of HospitalSanPablo,Asunción. Revistadel Nacional(Itauguá), 1(2), 44-52.http://scielo. iics.una.py/scielo.php?script=sci_abstract\&pid=\$2072-81742009000200009\&Ing $=e n \& n r m=i s o \&$ tlng=es

Mendoza Tascón, L. A., Benítez, D. I., Mendoza Tascón, L. I., Arias Guatibonza, M. D., Peñaranda Ospina, C. B. (2016). Epidemiología de la prematuridad, sus determinantes y prevención del parto prematuro. Revista chilena de obstetricia y ginecología, 81(4), 330-42. https://scielo.conicyt.cl/ scielo.php?script=sci_abstract\&pid=S0717-75262016000400012\&lng $=e n \& n r m=i s o \&$ tlng=en

Pacheco-Romero, J. (2018). Parto pretérmino, avances y retos: A manera de prólogo. Revista Peruana de Ginecología y Obstetricia, 64(3), 393-8. http://www.scielo. org.pe/scielo.php?script=sci_abstract\&pid=\$2304-51322018000300012\&In $\mathrm{g}=\mathrm{es} \& \mathrm{nrm}=\mathrm{iso} \&$ tIng=es

Rodríguez Márquez, A., Hernández Barrio, E., Villafuerte Reinante, J., Mesa Montero, Z. T., Hernández Cabrera, Y., López Rodríguez del Rey, A. M. (2012). Factores de riesgo asociados al parto pretérmino. MediSur, 17(4), 505-13. http://scielo.sld.cu/scielo.php?script=sci_abstract\&pid=S1727$897 \times 2019000400505 \& \operatorname{lng}=e s \& n r m=i s o \&$ tlng=es 